ARTICLE

https://doi.org/10.1057/s41599-020-0471-y

\title{
Citizen science in the social sciences and humanities: the power of interdisciplinarity
}

\author{
Loreta Tauginienė (10 $^{1 凶}$, Eglè Butkevičienè ${ }^{2}$, Katrin Vohland ${ }^{3}$, Barbara Heinisch ${ }^{4}$, Maria Daskolia ${ }^{5}$, \\ Monika Suškevičs ${ }^{6}$, Manuel Portela (D) ${ }^{7}$, Bálint Balázs (D) ${ }^{8} \&$ Baiba Prūse ${ }^{9}$
}

\begin{abstract}
Citizen science evolved through multiple disciplinary manifestations into a new field of study and a participatory method of enquiry. While most citizen science projects take place within problem-focused natural sciences, social sciences and humanities help understanding the human dimension and open a broad methodological spectrum for enriching scientific research with new approaches and for boosting public participation. In this paper, we use a meta-synthesis approach to explore how citizen science is practised in the so far less addressed social sciences and humanities by focusing on the role of the citizens, the goals and approaches of the projects, the tasks in which citizens are engaged and their gains across projects of diverse disciplinary background. Our findings indicate that social sciences are gaining more acknowledgment within interdisciplinary citizen science projects by addressing 'wicked' problems of human behaviour and agency, while humanities are in quest of a better-defined locus in citizen science. We conclude that social sciences and humanities still face considerable barriers to infiltrate citizen science; the payoffs are substantial and already rewarding for several subfields in social sciences and humanities.
\end{abstract}

\footnotetext{
${ }^{1}$ Office of the Ombudsperson for Academic Ethics and Procedures, Vilnius, Lithuania. ${ }^{2}$ Faculty of Social Sciences, Arts and Humanities, Kaunas University of Technology, Kaunas, Lithuania. ${ }^{3}$ Research Department Museum and Society, Museum für Naturkunde Berlin, Berlin, Germany. ${ }^{4}$ Centre for Translation Studies, University of Vienna, Vienna, Austria. ${ }^{5}$ Environmental Education Lab, School of Philosophy, National and Kapodistrian University of Athens, Athens, Greece. ${ }^{6}$ Institute of Agricultural and Environmental Sciences, Estonian University of Life Sciences, Tartu, Estonia. ${ }^{7}$ University Jaume I, Institute of New Imaging Technologies, Valencia, Spain. ${ }^{8}$ Environmental Social Science Research Group-ESSRG, Budapest, Hungary. ${ }^{9}$ Institute for Environmental Solutions, Priekuli, Latvia. ${ }^{凶}$ email: loreta.tauginiene@etikostarnyba.It
} 


\section{Introduction: Locus of social sciences and humanities in citizen science projects}

uring the last decade, an exciting trend has been recorded worldwide, with thousands of lay people from, in, and across different countries becoming engaged in citizen science (CS) projects, through various modes and channels of collecting, commenting, transcribing and analysing data. Variability in CS is high, with projects covering a vast array of topics, from bird observation to public health and bible study (Eitzel et al., 2017). The aspirations for supporting such activities are quite ambitious, with claims regarding the expected outcomes ranging from enabling the transition of research and policy towards sustainability (Petridis et al., 2017; West and Pateman, 2017), to participatory innovation (Hecker et al., 2018a) up to increased scientific literacy and responsive education (Bonney et al., 2016; Miczajka et al., 2015; Wals et al., 2014). All these claims are continuously debated from the CS policy perspective, too (Science Europe, 2018).

However, CS has been predominantly pursued within the realms of the natural sciences (Crain et al., 2014). Activities and projects following social sciences and humanities (SSH) topics and approaches are less easily discernible in CS practice, although they may be fuelled by some genuine and challenging questions (Heiss and Matthes, 2017). A survey of CS projects in Europe revealed that more than $80 \%$ of current CS practice is confined to life and natural sciences and only $11 \%$ to the social sciences and humanities (Hecker et al., 2018b). These findings point to a previous study (Heinisch, 2017), which demonstrates that among 1691 CS projects listed in several English-language and Germanlanguage project directories, almost $99 \%$ are contributory projects ${ }^{1}$. The latter study also shows that there are only a few published cases in which citizens held an active role in scientific procedures due to the method used, e.g. participatory action or collective intelligence. However, this is not in accordance to how CS was initially conceived and what stands as good CS practice, as, e.g. laid down in the ten principles proposed by the European Citizen Science Association (Robinson et al., 2018), all confirming that citizens should actively contribute to increasing the body of academic knowledge.

The underrepresentation of SSH may be due to several reasons. One of them is the stable and long-lasting bonds between CS and the natural sciences, with pioneer lay scientists mainly directing their interest towards the study of physical and natural phenomena by making use of positivistic methods of data collection and analysis. Such preponderant epistemological orientation in CS practice towards the natural sciences paradigm is coupled with an enduring controversy over the legitimacy of SSH and its academic status, and a growing turn of the interest among research funding schemes and institutions to more technocratic frames, goals and procedures in scientific enquiry (Heilbron et al., 2017). Furthermore, epistemological considerations interlink with methodological and ethical concerns when dealing with 'sensitive' SSH topics. They may also resonate a neoliberal drawback of academia and higher education and the transformation of universities into business-managerial enterprises with a technocratic orientation, where SSH became largely depoliticised and marginalised (Chan, 2011; Crawford, 2002; Tyfield et al., 2017). After all, SSH were soon categorised as junk science (as US politician Tom Coburn put it) (Geppert and Hollinshead, 2017). Hence, it is no surprise that for the time being $\mathrm{SSH}$ are underrepresented or hard to trace in CS practice.

SSH offer a long history and experience in fostering and reflecting the relationship and co-working practices between lay people and scientists, but predominantly under different terms such as participatory (action) research. Also, the translation of the term 'science' outside English speaking countries is broader and comprises humanities and social sciences, which in the backtranslation of 'citizen science', a broadly used term, may cause confusion. However, SSH is assumed to provide helpful methodological (especially epistemic) contributions to the growing field of CS. For all these reasons, further exploring the role and added value of SSH in CS practice and boosting a more prominent position for them in CS practice seem quite necessary.

Then, social sciences with an emancipatory role endow citizens to contribute to research and to inform policymakers using sciencebased evidence (Purdam, 2014). This allows democratising science and increasing its responsibility towards society (Corburn, 2005; Irwin, 1995; Lakshminarayanan, 2007; Lidskog, 2008; Purdam, 2014; Silvertown, 2009; Swan, 2012). Given these nuances, a closer look is necessary for boosting a more prominent position for them and understand their role. Moreover, CS has a potential avenue to demonstrate the value of SSH by integrating CS as an approach.

Nevertheless, mainstream CS practice has started to expand to new research foci and explore new avenues of citizen involvement that express a more open and genuine stance towards SSH and how to make room for them in the field. This has to do both with the need to broaden the realms of CS in terms of what has been traditionally dealt by as 'science', and to a renewed interest in developing an enriched understanding of how to promote and sustain citizen involvement in scientific research over some socially relevant but still uncharted CS topics. It has also to do with the need to instil an emancipatory role in the citizen's contribution to research; inform policymakers with new sciencebased evidence (Purdam, 2014); and lead to a democratisation of science and the awakening of its responsibility towards society (Corburn, 2005; Irwin, 1995; Lakshminarayanan, 2007; Lidskog, 2008; Purdam, 2014; Silvertown, 2009; Swan, 2012).

Our overarching research question is about the current and potential role of SSH in CS practice. Therefore, we ask how SSH could provide methodological frameworks to the growing field of CS and how the alleged added value of SSH in CS practice could be better deployed. The study reported in this paper further explicates the locus of SSH in CS projects by exposing where they meet with or differ from other fields of sciences. Our interest, therefore, focuses on what the current state of SSH in CS is, and whether there is a promising tendency towards building mutually rewarding interdisciplinary synergies for the sake of science and society. The paper begins with a description of the analytical framework that was elaborated to identify relevant areas of comparison within and across $\mathrm{SSH}$ as well as between $\mathrm{SSH}$ and natural and biomedical sciences in CS practice, based on a meta-synthesis of attentively selected publications. The findings are then presented and discussed with a view to investigating whether and how a closer bond between CS and SSH could change the way of doing research and boost citizen involvement in CS projects.

\section{Methodological approach}

Since the aim of the study was to develop a more integrated understanding of the extent and ways the SSH are represented and dealt with in current CS practice, a meta-synthesis methodology (Paterson et al., 2001; Zimmer, 2006) was adopted to identify and examine all related cases reported in the research literature. More particularly, meta-synthesis has been proposed as a qualitative method of enquiry offering the possibility to identify and integrate the contribution of different research studies to the generation of more formalised and robust knowledge (Zimmer, 2006). It is, therefore, a combined (analysis and interpretation) approach to individual studies developed within possibly different disciplinary fields and paradigms, diverse research foci and methodologies, aiming to prompt a more integrative understanding of the knowledge gained. 


\section{Table 1 Research questions and analytical units.}

\section{Research questions}

1. What methodological approaches and roles of citizens are used

by CS projects and activities claiming to pertain to $\mathrm{SSH}$ ?

2. What disciplinary fields within SSH do these CS projects encompass and what do diverse interdisciplinary synergies piece together?

3. What are the topics that have engrossed or attracted most of the interest of $\mathrm{CS}$ in $\mathrm{SSH}$ so far?

4. What purposes are defined to incorporate $\mathrm{SSH}$ in $\mathrm{CS}$ projects?

5. What are the benefits of citizen-generated data?

\section{Analytical units}

Research questions or hypotheses of the entire study

Research questions or hypotheses related to CS

Methods applied to the entire study

Methods applied to involve citizens

Role of citizens in the research cycle

Field of sciences (stated in the source)

Field of sciences (assigned by the authors)

Aim of the project/initiative

Aim of CS in the study

Theory/Assumptions used to explain the need for CS in the research

Types of collected data by citizens

Raw data availability to citizens

Type of publicising (applied to collected data)

Added value for citizens
As with any other research activity, a meta-synthesis needs to be framed with an appropriate research aim or question(s) in mind (Table 1). This framing directed processes regarding the location and identification of relevant papers in available databases, such as the search-and-retrieve strategies to be employed. Based on the aim of our study, five research questions were formulated as follows: (1) What methodological approaches and roles of citizens are used by CS projects and activities claiming to pertain to SSH? (2) What disciplinary fields within SSH do these CS projects encompass and what do diverse interdisciplinary synergies piece together? (3) What are the SSH topics that have engrossed or attracted most of the interest in CS practice so far? (4) What purposes are defined to incorporate SSH in CS projects? (5) What are the benefits of citizen-generated data? This set of research questions and related analytical units resulted from two workshops organised in 2018 within the COST Action CA15212 (https://cs-eu.net/), which already dealt with that overall question of SSH in CS. The first workshop was held at Kaunas University of Technology where 13 participants discussed the concept, methods and existing practices of CS in SSH (Butkevičiene, 2018a). The second workshop was held at the University of Geneva where 15 participants refined their discussion into more analytical categories (Butkevičienè, 2018b). Participants of both workshops had a different educational and professional background.

Given that the whole process of meta-synthesis involves more divergence than linearity, in order to ensure methodological quality, transparency related to steps and criteria is very important, e.g. from where and how the papers were located. In our study we opted for two of the largest databases: (a) Clarivate Analytics Core Collection (Science Citation Index Expanded, Social Science Citation Index, Arts \& Humanities Citation Index, Conference Proceeding Citation Index-Science Edition \& Social Science \& Humanities Edition) and (b) EBSCOhost research databases. Both databases are among the most well-known and widely used and provide access to papers published since 1990. Particularly, Clarivate Analytics is one of the major indexing and abstracting databases (Lor, 2018), and EBSCOhost is a product of EBSCO Information Services from the largest private companies in the area. Moreover, these two databases cover a wide range of disciplines and topics, including CS. This allowed us to extend our focus not only on journals related to the topic of CS (e.g., openaccess journal "Citizen Science: Theory and Practice"), but also to trace how CS topic is addressed in the light of interdisciplinarity, so in the thematically broad-scope journals. For this purpose, we chose two major well-known multidisciplinary databases.

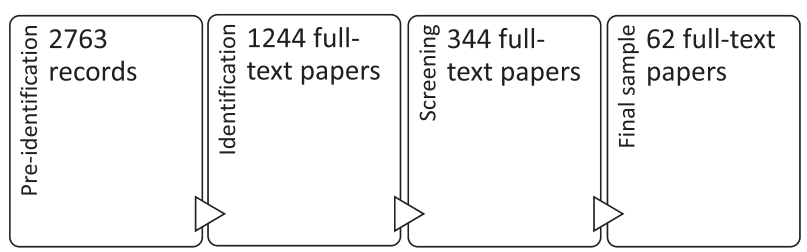

Fig. 1 Selection procedure for the papers to be reviewed.

While carrying out a focused screening of papers through these two databases and in order to avoid different connotations used under potential synonyms, a combination of two keywords only was used as subject terms/topics (e.g. citizen science AND social sciences $>\mathrm{TS}=($ citizen AND science) $\mathrm{AND}$ TS $=($ natural AND sciences)). Search results were retrieved twice, in October 2018 and in January 2019. Overall, 2763 records were retrieved (Fig. 1). Both databases suggested mostly the same papers, although the availability of the full texts differed.

As the second step, and in order to effectively proceed to the papers' selection, two authors of this paper (the first and second in order of appearance) selected solely the full texts available onsite (based on subscriptions of their universities) to avoid endless efforts to stabilise the sample. This, in turn, resulted in a sample of 1244 full-text papers. The same investigators used the manual perusal of titles, abstracts and keywords to endorse relevance for each of the papers (e.g. an explicit mention of CS, including alternative akin wording, such as 'citizen participation' or 'civic science'; or a clear mention of the field of sciences, such as social, environmental, etc.). This process led to the pre-final set of papers, a necessary step before determining the final set of papers for further analysis (Kullenberg and Kasperowski, 2016). Overall, 344 full-text papers in English, Spanish and French were identified and submitted to a preliminary meta-synthesis (Haddaway et al., 2015; Zimmer, 2006). Even then, not all 344 papers provided enough information. Moreover, some papers were metaanalyses themselves or focused on scientific outcomes only; therefore, they served to contextualise SSH within CS, and not as raw data.

Nevertheless, the 344 papers in the actual process of metasynthesis allowed us to develop a more in-depth view of each paper and determine a more refined list of them. To do so, we divided all papers by our expertise in the field (i.e. humanities, social, biomedical and natural sciences) and then distributed them equally among a field team along with a table containing the research questions and a list of the analytical units for the meta- 
synthesis (Table 1). Data are here named as analytical units which also served as the main inclusion criteria after the manual perusal of a full text.

Each investigator used a standard spreadsheet developed for the study, on which s/he kept detailed notes for each paper reviewed (horizontal rows) based on the analytical units (vertical columns). Each individual investigator proceeded to the metasynthesis of multiple studies in a related field and afterwards all nine met, discussed and agreed on the consolidation of their findings (the content in the cells of all individual spreadsheets). This approach both allowed a collective generation of knowledge and ensured multiple viewpoints.

Among the most important and recurrent issues raised by all investigators was that only a few studies provided comprehensive information about analytical units (Table 1). Discussions led to a critical appraisal of each paper's rigour and concluded with a refined final list of papers. In total, 62 papers were selected for being relevant and providing most of the data needed (Fig. 1). Out of these, 39 papers were located in the social sciences, five papers in the humanities, while two papers followed an interdisciplinary approach based on the SSH and the biomedical sciences and 16 papers on the SSH and the natural sciences. One paper (SSP4 and BSP1) overlapped in two data sets, social sciences and biomedical sciences, due to the equally distributed interdisciplinary approach taken. The full texts of these 62 papers constituted the final sample of our study, based on which we conducted the meta-synthesis.

After data extraction based on the same spreadsheet as before, the findings were compared and discussed. If any of the spreadsheets did not contain enough detail on a case, the full-text paper was consulted again.

To ease the readability of data analysis, we used in-text codes for the papers reviewed by the field of sciences, namely SSPsocial sciences, HP- humanities, BSP-biomedical sciences and $\mathrm{NSP}$-natural sciences. All papers are also included in the list of references with an in-text code in brackets.

Limitations. Although meta-synthesis approach has some reservations (Haddaway et al., 2015), these can be nevertheless addressed via different techniques. For example, to minimise subjective coding biases of different investigators, we allowed for multiple disciplines to be represented in our team and resolved any disagreements via group discussion. However, our study had some built-in limitations. First, the sample of papers in some fields of sciences was very small: papers presenting interdisciplinary synergies between $\mathrm{SSH}$ and biomedical sciences are only two, and with humanities only five. In addition to this, CS is a contested term with different meanings for different communities (e.g. Eitzel et al., 2017) and may accordingly be used differently by authors, especially in the field of SSH where this term is less common. To our knowledge, there is still an ongoing work in the COST Action 15212 related to the development of an ontology for CS projects. Therefore, a greater diversity in the terms used could help us locate more papers. Hence, generalisation in these fields of sciences is rather difficult. Second, data have been collected based on two databases (Clarivate Analytics Core Collection and EBSCOhost research databases); therefore, it might be that not all papers relevant to our research questions have been traced. Furthermore, since publication strategies differ across disciplines, not all papers relevant for this study could be identified in these databases. For example, the two databases do not cover monographs, edited volumes and (online) journals which are (still) in great demand in the humanities; this makes probable that they were not listed in these databases. Nevertheless, we are aware that the citizen (social) science and citizen humanities landscape is larger than our sample. Increasing the sample by including other databases, grey literature and other online sources is an important issue for future research.

\section{Findings}

\section{Social sciences}

Methodological approaches and roles of citizens. Though in several cases the research question(s) or hypotheses are not clearly defined, the general observation is that they are mostly demanddriven, i.e. questions were built in societal needs. Addressing societal needs is seen as a remarkable feature and highly valued in people's everyday life (e.g. integrating traditional and local knowledge into scientific research, social perception of science and scientific spaces, or youngsters' perception of digital technology, social design, participatory agenda-setting to fill knowledge gaps, success factors of crowdsourcing, emancipatory forms of social science research, reflective learning, learning curve of $\mathrm{CS})$. One common thread surface in exploring the actual design and methodological questions related to knowledge co-creation, engaging and emancipatory form of social sciences (e.g. about the best modes of participation, trust-building).

The methods applied to the entire study are two-fold. They range from the rather conventional (literature review, (online) survey, semi-structured interviews, focus groups, content analysis) to more creative and socially innovative formats (digital storytelling, action research, participatory research, crowdsourcing, social dilemma games). Methods for citizen involvement are most often digital (e.g. mobile devices, 3D web applications, sensors, and platforms), and only sometimes personal through, e.g. gamified experiments, public talks and media advertising. Using participant observation placed the citizens in the role of researchers: 'The volunteer observer methodology might enable and empower the citizen in the social research process and also facilitate the researching of issues where resources are limited and where populations are hard to reach' (SSP27, p. 385).

Schools and educational institutions are the typical places for involvement. The role of citizens in the research cycle most often remains contributory by taking part in data collection, and there are only a few cases that citizens are involved in the whole research process. Citizens are described as simple volunteers to collect distributed data, or how to enhance decision-making processes (SSP11).

Interdisciplinary synergies. CS projects in citizen social science are mostly related to interdisciplinary approaches when the issue has been analysed, taking lenses of different disciplines and integrating knowledge and methods. We identified (both as stated in the paper and assigned by the authors of this paper) 11 unique sub-fields of social and behavioural sciences (e.g. anthropology, communication, education, social and economic geography, political science, psychology, sociology, management, public policy and administration, urban studies and planning, and science and technology studies).

Regarding the fields of science, most papers $(N=20)$ identify a combination of several fields of science per paper (e.g. natural sciences and social sciences; natural sciences, social sciences and humanities; applied sciences and social sciences). This shows a highly interdisciplinary nature of CS projects in social sciences.

Further analysing sub-fields of sciences, we noticed the same tendency: the major part of papers $(N=30)$ combined several sub-fields of science, e.g. social geography, engineering, and humanities (SSP1), information technologies, spatial sciences and social sciences (SSP3), computational social science and behavioural sciences (SSP7), management and natural sciences (SSP11), natural sciences and social sciences (SSP14), or ecology 
and sociology (SSP34). It is important to note that some subfields of science are inwardly interdisciplinary. For example, nine papers identified that the research they carry out should be assigned to environmental sciences (in our classification that was assigned to the category 'one sub-field of sciences per paper'); however, by its definition environmental sciences are already an interdisciplinary field of science. The most frequent sub-field of social sciences, mentioned in the papers, was sociology. In total, 14 papers were assigned to this sub-field of science.

The liaison of the social sciences with CS emerges through the need to learn more about different facets of societal needs. We distilled a variety of facets based on the number of CS cases described in the aims of papers analysed $(N=39)$. The first facet refers to methodological solutions in CS practice, such as codesign of the study (SSP32), effective ways to reach open innovation (SSP18) or value and quality of data collected by citizens (SSP25, SSP27, SSP28, SSP29). The second facet describes managerial issues, such as risk communication (SSP13), disease and another post-event management (SSP16, SSP17, SSP19) or philanthropic marketing (SSP33). The third facet relates to policy development (SSP6, SSP8, SSP11, SSP23, SSP39). The fourth facet focuses on social and, where relevant, other challenges, such as ecological (SSP4, SSP6, SSP14) and urban agriculture (SSP26). The fifth facet relates to the social life of citizens, such as to monitor emotional arousal (SSP3), to find out social practices in specific spaces (SSP30) or examine the power of place (SSP20). The sixth facet addresses the influence of technology on citizens (SSP5, SSP2, SSP12, SSP21). Some other facets focus on cognition, such as epistemic cultures (SSP34), ethical and regulatory questions (SSP36, SSP38), reasons of cooperation (SSP35) or historical development (SSP24). In many projects the involvement of citizens in research contributed to the advancement of the science, so the needs of scientists too; however, there are very few CS projects that explain the benefits for citizens to be involved in research. Among these examples, we can list empowerment of active citizenship by giving citizens a voice and raising citizen awareness of a topic (e.g. post-disaster safety).

Purposes of incorporating SSH in CS projects. In some of the reviewed papers, social science theories are proposed as a frame of citizens' involvement and the mutual benefits for participants and science. For example, the use of social-psychological theories arguing that biological and health-related findings may be related to socio-cultural-economic conditions (SSP9). Critical social sciences and critical geographies serve as a critique about how commodification and neoliberalism build economic benefit around genomics and health data (SSP16). Additionally, CS theory may serve as a common ground to highlight the importance of citizen involvement. For example, SSP32 takes into consideration a vast literature on how to facilitate co-creation processes. However, despite citing such theories, not all the authors seem to consider citizen participation in all the stages, adopting discourses and practices in different degrees. Like, considering that citizens should have an active role (SSP30), or generalising the effects and opportunities of internet use and biodata availability for worldwide participation (SSP3).

Regarding knowledge creation, epistemic analyses pointed out how citizens create narratives while addressing the learning curve of scientific topics and explaining their purpose of participating in CS projects (SSP34). For example, how scientific research pays attention (and contributes) to social concerns and needs, and how co-creation and co-design processes can lead to answers to such needs (SSP32); indigenous knowledge preserved through oral tradition and cultural expressions, such as a conceptual background to as a 'broader and more multilayered understanding of the interconnection of humans' (SSP4, p. 085006-1). In general terms, the conceptual frameworks drawn from the social sciences helped to provide more weight to local people's knowledge, the expertise of the embodied experience, the situatedness and coproduction of transdisciplinary knowledge (SSP14) and contributed to creating an argument of trust around non-expert knowledge (SSP12, SSP22).

Benefits of citizen-generated data. The analysis of the reviewed papers revealed that citizens involved in social CS projects were asked to contribute to data collection by providing mainly personalised information but also other types of social data. Social data vary from behavioural information (e.g. personal genetic data (SSP16), their own body metrics and indicators (SSP9) or their bodily and emotional reactions to various states (SSP3) to tracking their mobility patterns in public spaces (SSP7)); attitudinal and opinion-based data (e.g. their personal views towards cooperation (SSP35) or how technology affects their life (SSP5), their judgements regarding participation in CS projects (SSP8, SSP32) or how to promote open innovation (SSP18), to expression of their political attitudes (SSP10) or ecological concerns (SSP11)); self-reports of individual practices and lifestyle patterns (e.g. their personal nutritional and exercise habits (SSP9), their points of interest in drawing some new footpaths in the area (SSP1) or their channels and practices of political communication (SSP10) to their modes of CS engagement and contribution (SSP22, SSP28)); information about risks and hazards (e.g. shared in person (SSP13) or elicited via social networks analysis (SSP17), or their experience about post-disaster situations (SSP19)); information, ideas and personal experiences on community change trends and other social issues (e.g. migration (SSP24), sustainable development (SSP23) and specific urban social practices (SSP27) and responses (SSP29)); and sociodemographic data to better understand specific situations and practices (SSP36, SSP37), or even for identifying marketing and consumer behaviour patterns (SSP33).

Most of the papers reviewed $(N=26)$ do not explicitly refer to whether and how they made raw data available to citizens involved. The rest of the papers reviewed mention either online data accessibility in general (SSP3, SSP26) or specify certain digital means and channels (e.g. specialised data management platforms or repositories (SSP17, SSP28), the project's webpage (SSP7, SSP29), the project's blog (SSP10), or even via email (SSP8)). One paper reported that the participants had no access to the raw data, but they could receive a personalised report of the results of their own (genetic) data analysis for free (SSP16). Finally, in one study (SSP26) participants were not only allowed to download the raw data, but also to visualise and interact with them as they were displayed in the results charts (e.g. charts could be downloaded, emailed or shared on social media).

The situation was similar with the means employed for publicising the collected data. Most of the papers reviewed $(N=27)$ do not specify whether and how they dealt with the issue at all. In a few studies there is a mention that the raw data and/or the project's results were made publicly available and publicised through knowledge exchange (SSP8) or by use of digital means (SSP13). Among the most commonly used means were (open access) scientific and research papers (SSP5, SSP6, SSP26, SSP32, SSP33) and the use of digital media, such as social networks and the project's website (SSP24).

Coming to what is identified by the citizens themselves as an added value from their participation in CS projects, they mentioned an acquired active scientific role instead of being the research subjects or mere informants. To get actively engaged in tasks traditionally implemented by formal scientists and professional researchers is a self-rewarding aspect of CS participation (SSP10), especially when this is coupled with an 
acknowledgement of their contribution in academic publications (SSP23). In terms of the learning gained, the citizens acknowledged increased awareness of the topic they engaged with (SSP11), augmented expertise after participation in training in social science research procedures (SSP23) or in any other specialised subjects (e.g. data quality (SSP22)), or as an outcome of the experience of participation itself (SSP27). These led them to feelings of satisfaction and a sense of empowerment which were further supported by open access to the project's data and availability of (digital) tools or more opportunities were provided for further data analysis according to their personal interests and needs (SSP9, SSP13), or even customisation of the research design and tools to develop their own new projects (SSP1).

A sense of empowerment to get in personal and community action and participate in informed decision-making and policymaking, especially for disadvantaged communities, was an alternative 'learning' benefit for the citizens (SSP4). Involvement with issues they are concerned about made their voice heard (SSP32). Moreover, the knowledge gained during the CS project served as inspiration and innovation for personal life (SSP3), the advancement of professional practice (SSP6) or discovery about personal health and well-being (SSP31). Finally, altruism-based satisfaction and the sense of serving a worthwhile goal (SSP31) may be juxtaposed with more mundane or monetary benefits (e.g. money coupons were offered as a reward for participation (SSP29)).

\section{Humanities}

Methodological approaches and roles of citizens. The research questions and methods of the reviewed papers relate to the involvement of society when collecting, processing and analysing sources (HP1), which gives researchers access to privileged information or new primary sources. Involving people may also lead to the modification of a project's methodology, objectives, results or dissemination. This is increased in the humanities and by digital technology use as well as social networks. Therefore, these studies examined the place of crowdsourcing activities within humanities research infrastructures (HP2) or reviewed the practice of public participation in three areas of digitisation (transcription, georeferencing and annotation) (HP3) or analysed platforms which help to disseminate projects (HP4). The findings show that these platforms usually list natural science projects which adopt a top-down approach and focus on data quantity, i.e. data collection (HP4). HP5, however, has a clear humanities focus, i.e. historical research into CS.

The research questions related to $\mathrm{CS}$ are rather on a meta-level $(N=3)$. For example, how to make the sciences and humanities work with and for society (HP1), how platforms deepen the relationship between science and society (HP4) or CS confines to professional science, scientific practice, and education (HP5). The given examples relate to the questioning of the boundaries of professional science, distinctions between scientific practice and education.

The methods applied in the meta-studies mostly follow a qualitative approach, e.g. case studies (HP1), literature reviews (HP2, HP4), content analysis (HP4), online surveys (HP2), interviews (HP2) and comparisons to create a typology of CS activities (HP3) or the study of historical documents (HP5). The methods applied to involve citizens are the use and creation of digital and analogue social networks, social media channels, media and institutions (HP1). These methods served for recruitment or involvement.

The roles of citizens in the research cycle were compiling, organising, analysing and sharing sources (HP1). These included data collection (HP1, HP4, HP5), documentation (e.g. georeferencing (HP1, HP3), mapping, annotation (HP3) and transcription of items (HP1, HP3)), or recovering sites with the help of local communities knowledgeable about protection of landscapes (HP1).

Interdisciplinary synergies. The fields of science stated in the paper reviewed are history (HP1, HP5), humanities (HP2), biodiversity research and digital humanities (HP3) and natural sciences, social sciences and humanities (HP4). The additional fields of science assigned by us are history and archaeology (HP1, HP5) and other humanities (HP3). This means that they are either focused on analysing or describing CS from a humanities perspective or on combining different disciplines.

The aims in the papers reviewed differ, e.g. to analyse CS initiatives (to compare three initiatives involving civil society (HP1); to analyse relationships between crowdsourcing and humanities research infrastructures (HP2); to analyse public participation in digitisation of biodiversity research specimens (HP3); to analyse the role of volunteers in the research process (HP4)) or provide a (historical) framework for CS (to explore the networks of participants engaged in science-related activities during the 19th century (HP5)).

Meanwhile, the aim of conducting CS was explained in a few papers (e.g. HP1). There are mentions of the aim to accelerate data capture for urgent social challenges (HP3), to improve knowledge, conservation of the natural environment and ensuring that big data follow protocols to guarantee scientific validity and applicability (HP4).

Purposes of incorporating SSH in CS projects. The assumptions used to explain the need for CS in the research refer to the claim that citizens are also actors in the humanities (e.g. in the historiographic process) and may help to save primary historical sources. The reasons for using CS are increased coverage, access to unpublished sources scattered almost all over the world and access to local knowledge of natural resources in a specific region (HP1). Other reasons are the acceleration of the research progress by giving educators, policymakers, researchers or the public access to collections, thereby addressing data quality in CS projects (HP3).

Humanities in CS projects are not pressured to increase the quantity of data or of volunteers involved in a project. However, in some CS projects, they intend to obtain big data at low cost. Also, in the humanities, CS projects are sometimes collaborative and virtual (reaching everyone who has a computer and internet). Nevertheless, they usually follow a top-down approach, i.e. volunteers collect vast amounts of data so that professional researchers can answer research questions and enhance academic progress (HP4). The coverage and the establishment of a distributed community of citizen scientists working with professionals, thus contributing to both their own scientific education and the advancement of science (HP5), was also mentioned.

Benefits of citizen-generated data. Since the papers reviewed rather analysed CS, the type of data collected by citizens was not clearly defined in a couple of reviewed papers (HP2, HP3). Citizens were asked to collect pictures, transcriptions, structured data of communities, own stories or local knowledge (HP1), environmental data (HP4) or rainfall observations (HP5). These data were used for genealogy, reciprocal exchange and communication, share and involvement of society, especially the local community (HP1), for research purposes (HP4) or in research papers (HP2). The raw data of CS projects were made available online (HP1, HP3, HP5). The data collected by users (citizens) were published on platforms (HP1) and could be used by diverse stakeholders, such as educators, policymakers, researchers and others (HP3). 
Interestingly, in the rainfall research, the researcher drew some conclusions on the motivation of users, stating that the volunteers have been creating a database which can be valuable for different fields (HP5). Although the paper analyses CS in natural sciences in the 19th century and compares it with the 21 st century CS, it uses methods inherent to humanities. The interplay of a few disciplines evidences a good way to enrich data and knowledge.

The added value for citizens includes a symbolic and emotional link with heritage as well as empowerment or socialisation of heritage, including identity formation and community building (HP1). This is exemplified by offline and online social networks allowing not only to collaborate, but also to create relationships and exchange knowledge between researchers and the general public. In addition, the accessibility of the methodology, the control over the data as well as the immediate publication of the work carried out and the creation of a digital contentful space were mentioned too. Citizens may benefit from participating in CS by acquiring field knowledge and skills, such as text annotation according to the Text Encoding Initiative guidelines (HP2). Furthermore, the increased public understanding of science, academic literacy (HP3, HP4, HP5) and personal development and lifelong learning (HP3, HP4, HP5) were mentioned too. Among other benefits for citizens, the reviewed papers listed items such as the personal benefit of appreciation (HP3) or contributing to science (HP5), 'social' rewards (e.g. through rankings, increased standing in the community or being credited and named in publications (HP2)).

\section{Biomedical sciences}

Methodological approaches and roles of citizens. The description of methodological approaches is quite scant. Only one paper explicitly states a research question to the entire study, e.g. how groups of 'citizen scientists' in non-traditional settings and primarily online networks claim to be challenging conventional genomic research processes and norms (BSP2). Solely qualitative approaches to the entire study are used for data analysis, such as thematic analysis and ethnography. The latter approach (ethnography) is traceable from the way how researchers describe the type of data and data collection. As the involvement of citizens is an all-the-time challenge for scientists, a snowball sampling approach was used. Citizens were asked to provide personal data about their social life, e.g. to explain spiritual and cultural aspects that affect their health and environment (BSP1) and to share 'their stated objectives, practices, and political and moral stances to institutions of expert scientific knowledge production' (BSP2, p. 494). Such a role of citizens testifies their contribution to data feeding, but this is not tantamount to a partnership in data collection as the definition of CS implies.

Interdisciplinary synergies. Ties with SSH are barely noticeable. Environmental health sciences intertwine with ethnology (BSP1). This conjunction derives from the study aim, e.g. to testify 'successful application of TEK [Traditional Ecological Knowledge] principles in federally funded research' in order to understand the interconnectedness of environmental factors and human health (exposome and social determinants of health) (BSP1, p. 085006-1).

Purposes of incorporating SSH in CS projects. The use of SSH in CS projects is explicated through the need to learn more about different health aspects (e.g. to better understand social regulation and cultural values which are paramount to both indigenous knowledge and health (BSP1)) or to claim a more active role of lay people as potential decision-makers of their health (e.g. 'people are no longer 'patients' but are instead 'participants' and instigators of their own health management plans' (BSP2, p. 496).
Benefits of citizen-generated data. The detail about what data citizens collected, what data were publicised and whether citizens had access to them is not provided. However, assumedly publishing of the reviewed papers serves this purpose to some extent. In addition to this, it is stated that citizens get the advantage of being involved in research that affects their health and the use of their personal data, e.g. 'better informed to develop models for sustainable practice and to create lasting policies that enhance the health and quality of life' (BSP1, p. 085006-6), learning 'the ethical and legal aspects of sharing genomic information' in terms of ownership and research conduct (BSP2, p. 508). These permit discovery of what other concerns citizens might have when immersing into an interaction with a scientist, and what social knowledge might be required to make their involvement safe and smooth.

\section{Natural sciences}

Methodological approaches and roles of citizens. Most papers originally selected and read do not refer to the role and tasks of citizens at all, and subsequently do not provide a theoretical framework how to address them. Rather often, data were analysed which were collected in other contexts and projects, or mined from databases. In the papers finally reviewed as they mention $\mathrm{SSH}$ components, mixed-methods approaches were the most commonly applied types of methodologies. A few papers $(N=5)$ had an explicitly qualitative orientation, using focus groups, individual interviews and/or participatory workshops (NSP1, NSP5, NSP6, NSP12, NSP13). Some papers have combined qualitative methods with quantitative social science methods, such as surveys (NSP3, NSP6, NSP10, NSP13). Certain papers referred explicitly to quantitative natural science methodologies (e.g. experiments, modelling), but additionally used some social sciences methods to engage with the citizen scientists (e.g. online webinars, educational events, instructions of dive masters) (NSP2, NSP8, NSP15, NSP16). Two papers included coproduction of CS web platforms together with various CS stakeholders (NSP1, NSP7).

In half of the reviewed papers, citizen scientists were involved as data collectors $(N=10)$. However, a few papers involved citizens in several steps of the research process, such as designing their own experiments and developing own research projects (NSP12, NSP13, NSP14), or collecting concerns and feelings about establishing new technologies (NSP4). In another study citizens served as observed objects when investigating how the observation of butterflies in their garden changed their behaviour patterns (NSP5).

Interdisciplinary synergies. The papers are mainly written from a natural scientist perspective with a strong focus on the epistemic scientific outcomes (e.g. NSP9, NSP15, NSP16). Citizens and their roles were rarely addressed beyond data collection. An interesting example is a more review-like study on civic monitoring (NSP8). The authors concluded that if both expertise from biological sciences and technology research (NSP13) and initiatives to develop integrated approaches to develop and evaluate environmental stewardship (NSP3, NSP14) came together, the intrinsic contradictions of human impact in citizens may turn into a more positive recognition of the role of humans.

Purposes of incorporating SSH in CS projects. Expertise from social sciences is involved to address the social dimension of specific projects. One example is the use of wave energy in Oregon. 'A multidisciplinary group of social scientists' (NSP4, p. 84) supports the integration of the stakes and interests of the local citizens. The other way around another project worked (NSP2): 
here results from a biological/environmental CS project-scuba diving-intended to inform educational programmes and research. Questionnaires to assess educational progress can be tagged as a method based in social sciences. Questionnaires are also used in other projects focusing on natural sciences (e.g. in order to understand the motivations of citizens or to improve practical or communicational challenges (NSP8)). Next to these, more evaluation-oriented methods, skills of social sciences are needed to co-create projects and enhance their social impact.

Benefits of citizen-generated data. The main or most visible users of the collected data are researchers. The question arises regarding the full integration of citizens in the use of the collected data and the initiation of CS projects. Most of the papers describe top-down (initiated by researchers) CS projects (e.g. NSP3, NSP16), although bottom-up (community-driven) approaches were also identified (NSP14).

The reviewed papers do not always specify the availability of the raw data; therefore, it remains unclear who is the genuine owner of the data.

There are a few papers with a clear statement that raisingawareness is the main added value for citizens (e.g. 'BugMap has proven efficient in stimulating scientific literacy and aided in raising public awareness' (NSP11, p. 14)). Also, there are papers which stress the inclusion of the collected data as part of a resource management activities (e.g. NSP14).

CS projects gain impact if they reflect more carefully the role of citizens, i.e. are more aware of the social dimension of the projects situated in the realm of natural sciences. Obviously, journals become more open, 'Insects' does not automatically imply a social dimension but hosts a relevant paper (NSP10).

\section{Discussion}

When mapping fields of sciences in citizen social science projects, two main focal points regarding interdisciplinary distribution were identified. First, in most papers two or three disciplines are combined to answer the research question. The second refers to one-discipline/one-field projects; however, some disciplines are of interdisciplinary character (e.g. environmental research). Overall, just slightly more than half of the 39 papers we assigned to social sciences explicitly indicate their belongingness to social sciences. All the reviewed humanities papers, however, state that they refer to the (digital) humanities. This implies that social sciences are invisible, i.e. hidden behind other sciences in CS projects.

Nevertheless, the presence of social science theories is approached infrequently in CS. Although, some concepts related to social organisation and citizen involvement are implicated in many assumptions (e.g. the need to collaborate with diverse stakeholders (SSP6), to transfer open innovation from private sector to public policies using knowledge of citizens (SSP18)). Most of these concepts helped to address the dichotomy between experts and laypeople, giving value to the plurality of voices and the richness of local knowledge. Social sciences help to untie those assumptions related to the organisation of citizens and their role in research projects. However, concepts that were drawn from their theory can cause several wrong assumptions about the motivations of citizens in participating in CS projects. As we saw in several studies, social sciences can provide frameworks and methodologies to address the complexities of interdisciplinary research and reduce the uncertainty around these assumptions. Social science concepts (e.g. interdisciplinary knowledge, public science, cooperative research, action research) could be helpful in facing the situatedness of knowledge creation and engage with people's knowledge, and embodied experiences.
The ways citizens are asked to contribute to research presents a great variability and richness. Their contribution mainly comes in the form of personalised information on various behavioural, cognitive and attitudinal aspects of individual and social human agency and experience, in relation to a range of social situations, phenomena and practices. Personal information, ideas and experiences can be further coupled with socio-demographic data, so that there is richness of evidence that comes forth in a multifaceted way.

Most of the raw data are either online accessible to the citizens or are sent to them as personalised analysis reports along with some extra tools to visualise and experiment. Publicity of the data is achieved through mainly (open access) papers, social networks and the project website. Both are recognised as important assets of a CS project that reinforce motivation for participation and cultivate a sense of connectedness with and appropriation of the project.

As to the added value of citizens' participation in CS, active involvement in scientific practice with formal scientists and professional researchers is most common, followed by various learning benefits and a sense of empowerment to transfer this knowledge to further research and/or to their personal and communal life.

Although the reviewed papers in humanities report an underdeveloped link to CS projects, they show that CS can contribute to identity formation, community building, acquiring knowledge and skills as well as to increase academic literacy. Regarding the participants' motivation, some of these papers assume that the motivation for people to participate voluntarily in CS includes the contribution to a greater good. Additionally, appreciation or social rewards through gaining standing in the community may also be important aspects why volunteers participate in CS. Interestingly, none of these reviewed papers mentions monetary rewards; however, the funding of such projects may have restrictions regarding establishment of prizes.

Furthermore, humanities have different approaches to CS. They use CS as a tool (e.g. crowdsourcing in the field of cultural heritage and digital humanities (Dobreva and Azzopardi, 2014; Oomen and Aroyo, 2011)), as this is a common practice in CS projects. In this respect, the term 'citizen humanities' was introduced (e.g. Adamson, 2016; Dunn and Hedges, 2018). In addition, the humanities may facilitate the meta-analysis of CS history which also holds partly true for social sciences (e.g. social scientists are somewhat more interested in studying CS than conducting it, but social sciences are already increasingly conducting citizen social science (SSP15)).

Research clustered under 'natural sciences' will enhance its impact when reflecting the role of citizens in more detail. A closer link to social sciences may enrich the theoretical framework and set of methodologies to solve the wicked problems of the sustainability turn which are often linked to different interests, perceptions, or routines.

Very few reviewed papers explicitly testify that though scientists do not envisage giving access to the citizen-generated data as the primary benefit of their study, other citizens reuse these data (e.g. geospatial data), particularly when published online, for different purposes, and provide durability for data after the project end (Craglia and Shanley, 2015). This implies accidental (unplanned) benefits of the latter contribution to data use (accidental contribution to CS). Another example of accidental contribution emerges when citizens enrich the dataset without knowing how their data will be further used (e.g. user's locations taken from his/her tweets) (Case et al., 2015).

The analysis of the reviewed papers does not explicitly evidence how citizen-generated data, published within a paper, was communicated to citizens to increase their benefits gained from taking part in CS. Therefore, further research is needed to explore 
whether and how scientists advertise their CS-related papers through online social networks. Usually, scientists are seen as isolated (Pilbeam and Denyer, 2009) and non-residents of online social networks (White and Le Cornu, 2011) (read more on typologies of users of online social networks in Tauginiene and Kalinauskaitè, 2018).

Finally, the claims about awareness-raising and similar outputs of CS projects are fairly well discussed. However, changes in human behaviour and cognition (particularly learning the level of pre-knowledge and post-knowledge about the topic) are not discussed (e.g. Fujitani et al., 2017).

\section{Conclusions}

Our research findings evidence the strong interdisciplinary character of SSH in CS projects. Quite often, social sciences are 'married' with environmental research or natural sciences and have a propensity towards biomedical sciences due to 'wicked' problems they are addressing. In this way, social sciences are less explicitly visible and recognisable within the interdisciplinary CS projects due to the general perception of science (e.g. an issue is situated in a specific field of sciences (e.g. climate change in natural sciences), but linked to values ascribed to SSH).

Though CS projects give room to harness SSH in order to gather rich data and to increase the body of interdisciplinary knowledge, we should admit that SSH are yet largely underutilised in CS. Some sub-fields of social science testify a better receptivity (e.g. psychology, management); however, some subfields of humanities are not yet part of CS. Therefore, social sciences seem preeminent due to their double role, doing research on CS practices and making their own projects to 'improve' the world (at least for the participants). Meanwhile, humanities are more neglected, so a rarity in science. Taking these points in mind, although the reflective role of SSH is discernible (e.g. via questionnaires/evaluation, ways of cooperation), this needs revisiting and strengthening the role of SSH in CS (e.g. to find out who the participants are). We do also believe that if the reflective potential and (inter/trans)-disciplinary skills of SSH is better utilised, CS will improve massively with regard to increasing sustainability if, on the one hand, SSH frameworks are applied more proactively to understand the socio-technical character of challenges, such as climate change or the loss of biodiversity, where value systems, economy, and governance system are in fact underlying factors, and, on the other hand, methodologies and skills from especially social sciences are applied to understand the motivation and learning processes of participants better to increase their self-efficiency, and the project outcomes and impacts.

\section{Data availability}

The datasets generated during the current study are available in the Zenodo repository, https://doi.org/10.5281/zenodo.3739352.

Received: 1 September 2019; Accepted: 8 April 2020;

Published online: 07 May 2020

\section{Notes}

1 Although there are different typologies for CS projects, Heinisch (2017) used in her study the typology developed by Bonney et al. (2009).

\section{References}

Adamson J (2016) Gathering the desert in an urban lab: designing the citizen humanities. In: Adamson J, Davis M (eds) Humanities for the environment: integrating knowledge, forging new constellations of practice. Routledge, London, pp. 106-119
Baumber A, Metternicht G, Ampt P, Cross R, Berry E (2018) From Importing innovations to co-producing them: transdisciplinary approaches to the development of online land management tools. Technol Innov Manag Rev 8 (8):16-26. (cited as NSP1)

Bocanegra Barbecho L, Toscano M, Delgado Anes L (2017) Co-creación, participación y redes sociales para hacer historia. Ciencia con y para la sociedad. Hist Comun Soc 22(2):325-346. (cited as HP1)

Bonney R, Ballard H, Jordan R, McCallie E, Phillips T, Shirk J, Wilderman CC (2009) Public participation in scientific research: defining the field and assessing its potential for informal science education. A CAISE Inquiry Group Report. Center for Advancement of Informal Science Education (CAISE), Washington

Bonney R, Phillips TB, Ballard HL, Enck JW (2016) Can citizen science enhance public understanding of science? Public Underst Sci 25(1):2-16

Branchini S, Meschini M, Covi C, Piccinetti C, Zaccanti F, Goffredo S (2015) Participating in a citizen science monitoring program: implications for environmental education. PLoS ONE 10(7):e0131812. (cited as NSP2)

Brovelli MA, Zamboni G (2015) A 3D social platform for the Paths of Via Regina. Int Arch Photogramm, Remote Sens Spat Inf Sci XL 4/W7:23-30. (cited as SSP1)

Butkevičienè E (2018a) Citizen science in social sciences and humanities. Zenodo https://doi.org/10.5281/zenodo.3727226

Butkevičienė E (2018b) Citizen science in social sciences and humanities. Zenodo https://doi.org/10.5281/zenodo.3727235

Case NA, MacDonald EA, Heavner M, Tapia AH, Lalone N (2015) Mapping auroral activity with Twitter. Geophys Res Lett 42:3668-3676

Chan DKK (2011) In search of an ethical university: a proposed East-West integrative vision. Ethics Educ 6(3):267-278

Chase SK, Levine A (2018) Citizen science: exploring the potential of natural resource monitoring programs to influence environmental attitudes and behaviors. Conserv Lett 11(2):e12382. (cited as NSP3)

Conway F, Stevenson J, Hunter D, Stefanovich M, Campbell H, Covell Z, Yin Y (2010) Ocean space, ocean place: the human dimensions of wave energy in Oregon. Oceanography 23(2):82-91. Special Issue. (cited as NSP4)

Corburn J (2005) Street science community knowledge and environmental health justice. MIT Press, Cambridge

Cosquer A, Raymond R, Prevot-Julliard A-C (2012) Observations of everyday biodiversity: a new perspective for conservation? Ecol Soc 17(4):2. (cited as NSP5)

Craglia M, Shanley L (2015) Data democracy-increased supply of geospatial information and expanded participatory processes in the production of data. Int J Digital Earth 8(9):679-693

Crain R, Cooper C, Dickinson JL (2014) Citizen science: a tool for integrating studies of human and natural systems. Annu Rev Environ Resour 39 (1):641-665

Crawford F (2002) Scholars give idea of 'The Idea of the University' serious thought. The Cornell Chronicle, October 24

Dobreva M, Azzopardi D (2014) Citizen science in the humanities: a promise for creativity. In: Papadopoulos GA (ed) Proceedings of the 9th international conference on knowledge, information and creativity support systems, Limassol, Cyprus, 6-8 November 2014. Cyprus Library, Cyprus, pp. 446-451

Dunlap MA, Tang AHT, Greenberg S (2015) Applying geocaching principles to site-based citizen science and eliciting reactions via a technology probe. Personal Ubiquitous Comput 19:897-913. (cited as SSP2)

Dunn S, Hedges M (2013) Crowd-sourcing as a component of humanities research infrastructures. Int J Humes Arts Comput 7(1/2):147-169. (cited as HP2)

Dunn S, Hedges M (2018) From the wisdom of crowds to going viral: the creation and transmission of knowledge in the citizen humanities. In: Herodotou C, Sharples M, Scanlon E (eds) Citizen inquiry: synthesising science and inquiry learning. Routledge, Abingdon, Oxon \& New York, pp. 25-41

Ehlers M, Woodgate P, Annoni A, Schade S (2014) Advancing digital earth: beyond the next generation. Int J Digit Earth 7(1):3-16. (cited as SSP3)

Eitzel MV, Cappadonna JL, Santos-Lang C, Duerr RE, Virapongse A, West SE, Kyba CCM, Bowser A, Cooper CB, Sforzi A, Metcalfe AN, Harris ES, Thiel M, Haklay M, Ponciano L, Roche J, Ceccaroni L, Shilling FM, Dörler D, Heigl F, Kiessling T, Davis BY, Jiang Q (2017) Citizen science terminology matters: exploring key terms. Citiz Sci: Theory Pract 2(1):1-20

Ellwood ER, Dunckel BA, Flemons P, Guralnick R, Nelson G, Newman G, Newman S, Paul D, Riccardi G, Rios N, Seltmann KC, Mast AR (2015) Accelerating the digitization of biodiversity research specimens through online public participation. Bioscience 65(4):383-396. (cited as HP3)

Ellwood ER, Kimberly P, Guralnick R, Flemons P, Love K, Ellis S, Allen JM, Best JH, Carter R, Chagnoux S, Costello R, Denslow MW, Dunckel BA, Ferriter MM, Gilbert EE, Goforth C, Groom Q, Krimmel ER, Lafrance R, Martinec JL, Miller AN, Minnaertgrote J, Nash T, Oboyski P, Paul DL, Pearson KD, Pentcheff ND, Roberts MA, Seltzer CE, Soltis PS, Stephens R, Sweeney PW, von Konrat M, Wall A, Wetzer R, Zimmerman C, Mast AR (2018) Worldwide Engagement for Digitizing Biocollections (WeDigBio): the 
biocollections community's citizen-science space on the calendar. Bioscience 68(2):112-124. (cited as NSP6)

Ferran-Ferrer N (2015) Volunteer participation in citizen science projects. Profesional de la Inf 24(6):827-837. (cited as HP4)

Finn S, Herne M, Castille D (2017) The value of traditional ecological knowledge for the environmental health sciences and biomedical research. Environ Health Perspect 125(8):085006. (cited as SSP4 and BSP1)

Fujitani M, McFall A, Randler C, Arlinghaus R (2017) Participatory adaptive management leads to environmental learning outcomes extending beyond the sphere of science. Sci Adv 3(6):e1602516

García-Peñalvo FJ (2017) El Proyecto WYRED. Educ Knowl Soc 18(3):7-14. (SSP5)

Garrett RD, Niles MT, Gil JDB, Gaudin A, Chaplin-Kramer R, Assmann A, Assmann TS, Brewer K, de Faccio Carvalho PC, Cortner O, Dynes R, Garbach K, Kebreab E, Mueller N, Peterson C, Reis JC, Snow V, Valentim J (2017) Social and ecological analysis of commercial integrated crop livestock systems: current knowledge and remaining uncertainty. Agric Syst 155:136-146. (cited as SSP6)

Geppert M, Hollinshead G (2017) Signs of dystopia and demoralization in global academia: reflections on the precarious and destructive effects of the colonization of the Lebenswelt. Crit Perspect Int Bus 13(2):136-150

Gutiérrez-Roig M, Sagarra O, Oltra A, Palmer JRB, Bartumeus F, Díaz-Guilera A, Perelló J (2016) Active and reactive behaviour in human mobility: the influence of attraction points on pedestrians. R Soc Open Sci 3:160177. (cited as SSP7)

Haddaway NR, Woodcock P, Macura B, Collins A (2015) Making literature reviews more reliable through application of lessons from systematic reviews. Conserv Biol 29(6):1596-1605

Hall DM, Gilbertz SJ, Anderson MB, Ward LC (2016) Beyond "buy-in": designing citizen participation in water planning as research. J Clean Prod 133:725e734. (cited as SSP8)

Hansen NV, Brændgaard P, Hjørnholm C, la Cour S (2014) Qualitative research building real-life interventions: user-involving development of a mindfulnessbased lifestyle change support program for overweight citizens. Eur J Clin Nutr 68:1129-1133. (cited as SSP9)

Hecker S, Bonney R, Haklay M, Hölker F, Hofer H, Goebel C, Gold M, Makuch Z, Ponti M, Richter A, Robinson L, Iglesias JR, Owen R, Peltola T, Sforzi A, Shirk J, Vogel J, Vohland K, Witt T, Bonn A (2018a) Innovation in citizen science-perspectives on science-policy advances. Citiz Sci: Theory Pract 3:1-14

Hecker S, Garbe L, Bonn A (2018b) The European citizen science landscape-a snapshot. In: Hecker S, Haklay M, Bowser A, Makuch Z, Vogel J, Bonn A (eds) Citizen science. Innovation in open science, society and policy. UCL, London, pp. 190-200

Heilbron J, Boncourt T, Schögler R, Sapiro G (2017) European social sciences and humanities (SSH) in a global context. http://www.eassh.eu/sites/default/files/ pages/INTERCO_SSH_final\%20funding.pdf

Heinisch B (2017) Degrees of participation in citizen science projects. an analysis of participatory projects listed in English-language and German-Language Citizen Science Project Directories. In: AGES (ed) Austrian citizen science conference 2017. Frontiers, Wien, pp. 15-20

Heiss R, Matthes J (2017) Citizen science in the social sciences: a call for more evidence. GAIA-Ecol Perspect Sci Soc 26(1):22-26. (cited also as SSP10)

Hill NJ, Tobin AJ, Reside AE, Pepperell JG, Bridge TCL (2016) Dynamic habitat suitability modelling reveals rapid poleward distribution shift in a mobile apex predator. Glob Change Biol 22(3):1086-1096. (cited as NSP7)

Hollow B, Roetman PEJ, Walter M, Daniels CB (2015) Citizen science for policy development: the case of koala management in South Australia. Environ Sci Policy 47:126-136. (cited as SSP11)

Hubbell BJ, Kaufman A, Rivers L, Schulte K, Hagler G, Clougherty J, Cascio W, Costa D (2018) Understanding social and behavioral drivers and impacts of air quality sensor use. Sci Total Environ 621:886-894. (cited as SSP12)

Irwin A (1995) Citizen science: a study of people, expertise and sustainable development, vol. 136. Routledge, London

Kar B (2016) Citizen science in risk communication in the era of ICT. Concurr Comput-Pract Exp 28(7):2005-2013. (cited as SSP13)

Krasny ME, Russ A, Tidball KG, Elmqvist T (2014) Civic ecology practices: participatory approaches to generating and measuring ecosystem services in cities. Ecosyst Serv 7:177-186. (cited as NSP8)

Krueger T, Maynard C, Carr G, Bruns A, Mueller EN, Lane S (2016) A transdisciplinary account of water research. WIREs Water 3:369-389. (cited as SSP14)

Kullenberg C, Kasperowski D (2016) What is citizen science?-A scientometric meta-analysis. PLoS ONE 11(1):e0147152. (cited also as SSP15)

Lakshminarayanan S (2007) Using citizens to do science versus citizens as scientists. Ecol Soc 12(2):11-23

Le Féon V, Henry M, Guilbaud L, Coiffait-Gombault C, Dufrêne E, Kolodziejczyk E, Kuhlmann M, Requier F, Vaissière BE (2016) An expert-assisted citizen science program involving agricultural high schools provides national patterns on bee species assemblages. J Insect Conserv 20(5):905-918. (cited as NSP9)

Lee SSJ (2017) Consuming DNA: the good citizen in the age of precision medicine. Annu Rev Anthropol 46:33-48. (cited as SSP16)

Lidskog R (2008) Scientised citizens and democratised science. Re-assessing the expert-lay divide. J Risk Res 11(1):69-86

Liu SB (2014) Crisis crowdsourcing framework: designing strategic configurations of crowdsourcing for the emergency management domain. Comput Supported Coop Work 23:389-443. (cited as SSP17)

Lor PJ (2018) International and comparative librarianship: a thematic approach. KG Saur Verlag GmbH

Loukis E, Charalabidis Y, Androutsopoulou A (2017) Promoting open innovation in the public sector through social media monitoring. Gov Inf Q 34 (1):99-109. (cited as SSP18)

Lynch LI, Dauer JM, Babchuk WA, Heng-Moss T, Golick D (2018) In their own words: the significance of participant perceptions in assessing entomology citizen science learning outcomes using a mixed methods approach. Insects 9 (1):16. (cited as NSP10)

Mabon L, Kawabe M (2017) Making sense of complexity in risk governance in post-disaster Fukushima fisheries: a scalar approach. Environ Sci Policy 75:173-183. (cited as SSP19)

Malek R, Tattoni C, Ciolli M, Corradini S, Andreis D, Ibrahim A, Mazzoni V, Eriksson A, Anfora G (2018) Coupling traditional monitoring and citizen science to disentangle the invasion of Halyomorpha halys. ISPRS Int J GeoInf 7(5):171. (cited as NSP11)

Marchezini V, Trajber R, Olivato D, Munõz VA, de Oliveira Pereira F, Oliveira Luz AE (2017) Participatory early warning systems: youth, citizen science, and intergenerational dialogues on disaster risk reduction in Brazil. Int J Disaster Risk Sci 8(4):390-401. (cited as NSP12)

Matz J, Wylie S, Kriesky J (2017) Participatory air monitoring in the midst of uncertainty: residents' experiences with the speck sensor. Engag Sci Technol Soc 3:464-498. (cited as NSP13)

McGowan ML, Choudhury S, Juengst ET, Lambrix M, Settersten Jr. RA, Fishman JR (2017) "Let's pull these technologies out of the ivory tower": the politics, ethos, and ironies of participant-driven genomic research. BioSocieties 12 (4):494-519. (cited as BSP2)

Miczajka VL, Klein A-M, Pufal G (2015) Elementary school children contribute to environmental research as citizen scientists. PLoS ONE 10(11):e0143229

Newman G, Chandler M, Clyde M, McGreavy B, Haklay M, Ballard H, Gray S, Scarpino R, Hauptfeld R, Mellor D, Gallo J (2017) Leveraging the power of place in citizen science for effective conservation decision making. Biol Conserv 208:55-64. (cited as SSP20)

Nov O, Arazy O, Anderson D (2014) Scientists@Home: what drives the quantity and quality of online citizen science participation? PLoS ONE 9(4):e90375. (cited as SSP21)

Oomen J, Aroyo L (2011) Crowdsourcing in the cultural heritage domain. In: Foth M, Kjeldskov J, Paay J (eds) Proceedings of the 5th international conference on communities and technologies, Brisbane, Australia, 29 June-2 July 2011. ACM Press, New York

Paterson BL, Thorne SE, Canam C, Jillings C (2001) Meta-study of qualitative health research: a practical guide to meta-analysis and meta-synthesis. Sage, Thousand Oaks

Peters CB, Zhan Y, Schwartz MW, Godoy L, Ballard HL (2017) Trusting land to volunteers: how and why land trusts involve volunteers in ecological monitoring. Biol Conserv 208:48-54. (cited as SSP22)

Petridis P, Fischer-Kowalski M, Singh SI, Noll D (2017) The role of science in sustainability transitions: citizen science, transformative research, and experiences from Samothraki island, Greece. Isl Stud J 12(1):115-134. (cited also as SSP23)

Pilbeam C, Denyer D (2009) Lone scholar or community member? The role of student networks in doctoral education in a UK management school. Stud High Educ 34(3):301-318

Pitarch Calero K, Valls AD, Llorens AB (2017) Migraciones de valencianos y sus descendientes en Cataluña Un ejemplo de Ciencia Ciudadana. Aposta 75:35-73. (cited as SSP24)

Pohoryles RJ (2017) Back to the future? From pragmatic approaches in the social sciences to the development of the patchwork theory. Innovation 30(1):5-23. (cited as SSP25)

Pollard G, Roetman P, Ward J (2017) The case for citizen science in urban agriculture research. Future Food 5(3):9-20. (cited as SSP26)

Purdam K (2014) Citizen social science and citizen data? Methodological and ethical challenges for social research. Curr Sociol 62(3):374-392. (cited also as SSP27)

Ratnieks FLW, Schrell F, Sheppard RC, Brown E, Bristow OE, Garbuzov M (2016) Data reliability in citizen science: learning curve and the effects of training method, volunteer background and experience on identification accuracy of insects visiting ivy flowers. Methods Ecol Evol 7:1226-1235. (cited as SSP28)

Robinson LD, Cawthray JL, West SE, Bonn A, Ansine J (2018) Ten principles of citizen science. In: Hecker S, Haklay M, Bowser A, Makuch Z, Vogel J, Bonn 
A (eds) Citizen science. Innovation in open science, society and policy. UCL Press, London, pp. 27-40

Roelfsema C, Thurstan R, Beger M, Dudgeon C, Loder J, Kovacs E, Gallo M, Flower J, Gomez Cabrera K, Ortiz J, Lea A, Kleine D (2016) A citizen science approach: a detailed ecological assessment of subtropical reefs at Point Lookout, Australia. PLoS ONE 11(10):e0163407. (cited as NSP14)

Sagarra O, Gutiérrez-Roig M, Bonhoure I, Perelló J (2016) Citizen science practices for computational social science research: the conceptualization of pop-up experiments. Front Phys 3:article 93. (cited as SSP29)

Sanz Hernández A, Bacallao-Pino LM (2015) Places making: Construcción participada de ciudades de cultura científica. Política Soc 52(3):793-817. (cited as SSP30)

Schröter M, Kraemer R, Mantel M, Kabisch N, Hecker S, Richter A, Neumeier V, Bonn A (2017) Citizen science for assessing ecosystem services: status, challenges and opportunities. Ecosyst Serv 28:80-94. (cited as SSP31)

Science Europe Briefing Paper on Citizen Science. (2018) D/2018/13.324/2. June (cited as Science Europe)

Senabre E, Ferran-Ferrer N, Perelló J (2018) Diseño participativo de experimentos de ciencia ciudadana. Comunicar XXVI(54):29-38. (cited as SSP32)

Shuttleworth S (2015) Old weather: citizen scientists in the 19th and 21st centuries. Sci Mus Group J 3:156-176. (cited as HP5)

Silvertown J (2009) A new dawn for citizen science. Trends Ecol Evol 24(9):467-471

Spellman KV, Mulder CPH (2016) Validating herbarium-based phenology models using citizen-science data. Bioscience 66(10):897-906. (cited as NSP15)

Swan M (2012) Crowdsourced health research studies: an important emerging complement to clinical trials in the public health research ecosystem. J Med Internet Res 14(2):e46

Tauginienè L, Kalinauskaite R (2018) Participation of doctoral students in online social networks. Stud Grad Postdr Educ 9(2):144-164

Tsai TT-H, Lin AJ, Li EY (2014) The effect of philanthropic marketing on brand resonance and consumer satisfaction of CSR performance: does media selfregulation matter? Chin Manag Stud 8(3):527-547. (cited as SSP33)

Tyfield D, Lave R, Randalls S, Thorpe C (2017) The routledge handbook of the political economy of science, 1st edn. Routledge, London and New York

Vallabh P, Lotz-Sisitka H, O’Donoghue R, Schudel I (2016) Mapping epistemic cultures and learning potential of participants in citizen science projects. Conserv Biol 30(3):540-549. (cited as SSP34)

Vicens J, Perelló J, Duch J (2018) Citizen Social Lab: a digital platform for human behavior experimentation within a citizen science framework. PLoS ONE 13 (12):e0207219. (cited as SSP35)

Walker CM, Colton Flynn K, Ovando-Montejo GA, Ellis EA, Frazier AE (2017) Does demolition improve biodiversity? Linking urban green space and socioeconomic characteristics to avian richness in a shrinking city. Urban Ecosyst 20(6):1191-1202. (cited as SSP36)

Wals AEJ, Brody M, Dillon J, Stevenson RB (2014) Convergence between science and environmental education. Science 344:583-584

Weltersbach MS, Strehlow HV, Ferter K, Klefoth T, de Graaf M, Dorow M (2018) Estimating and mitigating post-release mortality of European eel by combining citizen science with a catch-and-release angling experiment. Fish Res 201:98-108. (cited as NSP16)

West S, Pateman R (2017) How could citizen science support the Sustainable Development Goals? Discussion brief. Stockholm Environment Institute, Stockholm

Wexler A (2017) The social context of "do-it-yourself" brain stimulation: neurohackers, biohackers, and lifehackers. Front Hum Neurosci 11:224. (cited as SSP37)

White DS, Le Cornu A (2011) Visitors and residents: a new typology for online engagement. First Monday 16(9):1-8

Woolley JP, McGowan ML, Teare HJ, Coathup V, Fishman JR, Settersten RA Jr, Sterckx S, Kaye J, Juengst ET (2016) Citizen science or scientific citizenship?
Disentangling the uses of public engagement rhetoric in national research initiatives. BMC Med Eth 17(1):33 (cited as SSP38)

Zilliox S, Smith JM (2018) Colorado's fracking debates: citizen science, conflict and collaboration. Sci Cult 27(2):221-241. (cited as SSP39)

Zimmer L (2006) Qualitative meta-synthesis: a question of dialoguing with texts. J Adv Nurs 53(3):311-318

\section{Acknowledgements}

This publication is based upon work from COST Action CA 15212 Citizen Science to promote creativity, scientific literacy, and innovation throughout Europe supported by COST (European Cooperation in Science and Technology). We do also thank Maria Begoña Peña Lang, a researcher at the University of the Basque Country UPV/EHU (Spain), for her helpful comments on the initial research design.

\section{Author contributions}

LT contributed to the design of the methodological approach, identified papers for data analysis, analysed the selected papers in biomedical and social sciences and wrote the manuscript. EB contributed to the design of the methodological approach, identified papers for data analysis, analysed the selected papers in social sciences and wrote the manuscript. KV and MS contributed to the design of the methodological approach, analysed the selected papers in natural sciences and wrote the manuscript. MP and MD analysed the selected papers in social sciences and wrote the manuscript. BB analysed the selected papers in social sciences and wrote the manuscript. BP analysed the selected papers in natural sciences and wrote the manuscript. $\mathrm{BH}$ analysed the selected papers in humanities and wrote the manuscript. All co-authors read and approved the final manuscript.

\section{Competing interests}

The authors declare no competing interests.

\section{Additional information}

Correspondence and requests for materials should be addressed to L.T

Reprints and permission information is available at http://www.nature.com/reprints

Publisher's note Springer Nature remains neutral with regard to jurisdictional claims in published maps and institutional affiliations.

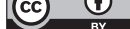

Open Access This article is licensed under a Creative Commons Attribution 4.0 International License, which permits use, sharing, adaptation, distribution and reproduction in any medium or format, as long as you give appropriate credit to the original author(s) and the source, provide a link to the Creative Commons license, and indicate if changes were made. The images or other third party material in this article are included in the article's Creative Commons license, unless indicated otherwise in a credit line to the material. If material is not included in the article's Creative Commons license and your intended use is not permitted by statutory regulation or exceeds the permitted use, you will need to obtain permission directly from the copyright holder. To view a copy of this license, visit http://creativecommons.org/ licenses/by/4.0/

(C) The Author(s) 2020 